\title{
Interferon for hepatitis B: US experience
}

\author{
R P Perrillo
}

\begin{abstract}
This paper reviews the results of recent studies carried out in the USA on the treatment of chronic hepatitis $B$ with interferon alfa-2b. In the US multicentre trial, $37 \%$ of patients lost hepatitis $B$ e antigen (HBeAg) and hepatitis $B$ virus (HBV)-DNA when treated with 5 million units (MU) daily for 16 weeks, compared to $42 \%$ in the US National Institutes of Health (NIH) trial treated with $10 \mathrm{MU}$ thrice weekly for 16 weeks. In both studies, the loss of HBeAg and HBV-DNA was associated with virological, biochemical, histological, and clinical improvement. Long term follow up in the National Institutes of Health study showed that $65 \%$ of responders had disappearance of HBsAg over a mean of four years, suggesting that termination of the $\mathrm{HBV}$ carrier state may be possible.

(Gut 1993; supplement: S95-S96)
\end{abstract}

\section{US multicentre trial}

On a conceptual basis, interferon should be an ideal agent for the treatment of chronic hepatitis $B$ because it is both immunomodulatory and antiviral. The early clinical trials suggested, however, that only $20-30 \%$ of patients responded to this agent.

The use of recombinant interferon alfa- $2 b$ has been evaluated more rigorously in a recent United States multicentre trial involving 169 patients. In this study, $37 \%$ of patients lost hepatitis $\mathrm{B}$ e antigen ( $\mathrm{HBeAg}$ ) and hepatitis $\mathrm{B}$ virus (HBV)-DNA when treated with 5 million units (MU) of interferon daily for 16 weeks (Table). ${ }^{12}$ An additional $8 \%$ of the treated patients had a sustained loss of HBV-DNA unaccompanied by clearance of $\mathrm{HBeAg}$. In this study, the rate of $\mathrm{HBeAg}$ seroconversion in patients treated with $1 \mathrm{MU}$ of interferon daily was not significantly different from that observed in untreated controls $(17 \%$ and $7 \%$, respectively).

\section{National Institutes of Health trial}

A recent randomised controlled trial involving 47 patients conducted at the National

TABLE Results with recombinant interferon alfa- $2 b$ in two recent US trials

\begin{tabular}{lllll}
\hline & No & Dose & $\begin{array}{l}\text { Loss of HBeAg } \\
\text { and HBV-DNA } \\
(\%)\end{array}$ & $\begin{array}{l}\text { Treatment stopped } \\
\text { because of side effects } \\
(\%)\end{array}$ \\
\hline US multicentre trial $^{1}$ & 85 & $\begin{array}{l}5 \text { MU daily for 16 weeks } \\
10 \mathrm{MU} \text { thrice weekly for } \\
16 \text { weeks }\end{array}$ & $\begin{array}{l}37 \\
42\end{array}$ & 3 \\
\hline $\mathrm{NIH}^{2}$ & 47 & 7 \\
\hline
\end{tabular}

$\mathrm{NIH}=$ National Institutes of Health
Institutes of Health (NIH), has shown that a similar response to that achieved with $5 \mathrm{MU}$ daily is obtained when patients are treated with 10 MU three times weekly for 16 weeks (Table). In this study, $42 \%$ of treated patients and $5 \%$ of controls underwent $\mathrm{HBeAg}$ seroconversion $(p=0.003)$. In the US multicentre trial, 3\% of patients stopped treatment early because of adverse effects compared with 7\% of treated patients in the NIH trial, thus suggesting slightly better tolerability when lower doses are given daily.

In these studies, the loss of $\mathrm{HBeAg}$ and HBV-DNA has been associated with virological, biochemical, histological, and clinical improvement. For example, a return to normal of raised aminotransferase activities occurred in nearly $90 \%$ of responders in the US multicentre study. Responders often reported decreased symptoms, particularly lessening of fatigue, and liver biopsies done within six to nine months of completing treatment showed improvement in piecemeal necrosis $(p=0 \cdot 03)$. Prolonged follow up (two to seven years) of patients in the USA has shown that reactivated infection occurs in the minority of responders (approximately $5-10 \%)$. This usually develops within a year of stopping treatment. Patients in whom the disease reactivates have generally responded to a second course of treatment.

\section{Long term follow up}

It has recently been recognised that some patients who become $\mathrm{HBeAg}$ negative as a result of treatment eventually become HBV surface antigen (HBsAg) negative upon prolonged follow up. In a study from the NIH, the disappearance of HBsAg was documented in 13 of 20 responders $(65 \%)$ during an average follow up interval of three years. ${ }^{3}$ HBV-DNA was no longer detectable in serum by polymerase chain reaction (PCR) at the time of, or shortly after, the disappearance of HBsAg. These data suggest that termination of the HBV carrier state may be possible in some patients. In studies conducted at Washington University and the NIH, investigators have been able to detect HBV-DNA in liver tissue several years after spontaneous or treatment induced HBsAg seroconversion. ${ }^{4}$ Quantitative evaluation of the PCR product in the Washington University study generally showed low HBV-DNA values that fell progressively as the follow up interval lengthened. The molecular form and function of this DNA is not known, but it is possible that the turnover of aging and infected hepatocytes leads ultimately to its complete elimination. Investigators at Washington University have 
also recently reported the results of long term histological observation (two to six years) in HBsAg negative patients with a post diagnosis of chronic hepatitis $B$. This study showed the absence of disease progression and an even greater degree of histological improvement than that observed when patients underwent biopsy within a year of stopping treatment. While the results are encouraging, further studies are needed to evaluate whether complete resolution of liver disease and total eradication of infection is possible.
1 Perrillo RP, Schiff ER, Davis DL, et al. A randomized, control trial of interferon alfa-2b alone and after
prednisone withdrawal for the treatment of chronic prednisone withdrawal for the treatment
hepatitis B. NEngl $\mathcal{}$ Med 1990; 323: 295-301.

$2 \mathrm{Di}$ Bisceglie AM, Bergasa NV, Fong TL, et al. A randomized, controlled trial of recombinant alpha interferon therapy for chronic hepatitis B. Hepatology 1991; 13: 70A.

3 Korenman J, Baker B, Waggoner J, et al. Long-term remission of chronic hepatitis B after alpha-interferon therapy. Ann Intern Med 1991; 114: 629-34.

4 Kuhns M, McNamara A, Mason A, Campbell C, Perrillo R. Serum and liver hepatitis B virus DNA in chronic hepatitis B after sustained loss of surface antigen. Gastroenterology 1991; 103: 1649-56.

5 Fong TL, Di Bisceglie AM, Feinstone SM, Waggoner JG, Axiotis CA, Hoofnagle JH. Persistent HBV DNA after Axiotis CA, Hoofnagle $\mathrm{JH}$. Persistent $\mathrm{HBV}$ DNA after
clearance of $\mathrm{HBsAg}$ from serum of patients with chronic hepatitis B. Hepatology 1991; 14: 130A. 